\title{
Heart rate variability and arrhythmic patterns of 24-hour Holter electrocardiography among Nigerians with cardiovascular diseases
}

This article was published in the following Dove Press journal:

Vascular Health and Risk Management

29 June 2015

Number of times this article has been viewed

\author{
Rasaaq Ayodele Adebayo \\ Amanze Nkemjika Ikwu \\ Michael Olabode Balogun \\ Anthony Olubunmi \\ Akintomide \\ Olufemi Eyitayo Ajayi \\ Victor Oladeji Adeyeye \\ Tuoyo Omasan Mene- \\ Afejuku \\ Olaniyi James Bamikole \\ Suraj Adefabi Ogunyemi \\ Adeola Olubunmi Ajibare \\ Omolola Abiodun Oketona \\ Cardiology Unit, Department \\ of Medicine, Obafemi Awolowo \\ University Teaching Hospitals \\ Complex (OAUTHC), lle-Ife, Osun \\ State, Nigeria
}

Background: Facilities for Holter electrocardiography (ECG) monitoring in many Nigerian hospitals are limited. There are few published works in Nigeria on the use of 24-hour Holter ECG in cardiac arrhythmic evaluation of patients with cardiovascular diseases.

Objective: To study the clinical indications, arrhythmic pattern, and heart rate variability (HRV) among subjects referred for 24-hour Holter ECG at our Cardiac Care Unit.

Methods: Three-hundred and ten patients (134 males and 176 females) were studied consecutively over a 48-month period using Schiller type (MT-101) Holter ECG machine.

Results: Out of the 310 patients reviewed, 134 were males (43.2\%) and 176 were females (56.8\%). The commonest indication for Holter ECG was palpitation followed by syncope in $71(23 \%)$ and $49(15.8 \%)$ of subjects, respectively. Premature ventricular complex and premature atrial complex were the commonest types of arrhythmia in $51.5 \%$ and $15 \%$ subjects, respectively. Ventricular arrhythmia was more prevalent in dilated cardiomyopathy patients (85.7\%). The HRV of subjects with palpitation, stroke, and diabetes mellitus with autonomic neuropathy, using standard deviation of normal to normal intervals average (milliseconds), were 107.32 $\pm 49.61,79.15 \pm 49.15$, and 66.50 \pm 15.54 , respectively. The HRV, using standard deviation of averages of normal to normal intervals average (milliseconds), of patients with palpitation, stroke, and diabetes mellitus with autonomic neuropathy were $77.39 \pm 62.34,57.82 \pm 37.05$, and $55.50 \pm 12.71$, respectively.

Conclusion: Palpitation and syncope were the commonest indications for Holter ECG among our subjects. The commonest arrhythmic patterns were premature ventricular complex and premature atrial complex, with ventricular arrhythmia being more prevalent in dilated cardiomyopathy. There was a reduction in HRV in patients with stroke and diabetic autonomic neuropathy.

Keywords: heart rate, arrhythmia, Holter electrocardiography, cardiovascular diseases, Nigerians

\section{Introduction}

Cardiac arrhythmias are disorders of the rate, rhythm, and conduction of cardiac impulses. ${ }^{1}$ Abnormalities of cardiac rhythm are most often, but not invariably a symptom of cardiac disease. Ambulatory Holter electrocardiography (ECG) was first introduced by the biophysicist Norman J Holter in 1949 to allow ambulatory home ECG monitoring of patients with suspected cardiac arrhythmias, and has been found useful in evaluating heart rate variability (HRV) pattern, ST segment analysis in cardiac ischemia, efficacy and safety of anti-arrhythmic or non-pharmacological therapies, among other uses. ${ }^{2-4}$ However, facilities for Holter ECG monitoring in many Nigerian hospitals are limited and there are very few published works on the
Correspondence: Rasaaq Ayodele

Adebayo

Cardiology Unit, Department of

Medicine, Obafemi Awolowo University,

PO Box 196I, Ile-Ife, Osun State, Nigeria

Tel +2348037149610

Email aderasaaq@yahoo.co.uk 
use of 24-hour Holter ECG in evaluating cardiac arrhythmia in patients with cardiovascular diseases. ${ }^{5-8}$

We therefore prospectively studied the clinical indications, arrhythmic pattern, and HRV among the subjects referred for 24-hour Holter ECG at the Cardiac Care Unit of Obafemi Awolowo University Teaching Hospitals Complex (OAUTHC), Ile-Ife, Osun State, Nigeria. This will assist in determining the pattern of Holter ECG in these subjects, and the information obtained will also contribute to the Nigerian and global database on 24-hour Holter ECG.

\section{Materials and methods}

This is a descriptive cross-sectional study in which 310 consecutive patients referred for 24-hour Holter ECG over a 48-month period were studied using Schiller type (MT-101) Holter ECG machine. Ethical approval was obtained from ethics and research committee of OAUTHC and all participants gave informed consent.

A thorough explanation of the nature of the test and handling of the recorder was given to each subject, and the Holter monitor was strapped to the subject's waist with the channel leads appropriately placed on the chest. ${ }^{9}$ The subjects were told to go home, continue their normal activities, and to return after 24 hours with the Holter monitor. The recordings were subsequently analyzed using Schiller's Cardiovit CS-200 digital ECG computer system. Each Holter ECG event recording was also manually analyzed according to standards ${ }^{10}$ by an experienced cardiologist and two senior registrars. HRV, using standard deviation of normal to normal intervals (SDNN) of ECG recordings and standard deviation of averages of normal to normal intervals (SDANN) in all 5-minute segments of the entire ECG recording, and ST segment changes were also analyzed according to standards. ${ }^{10}$ The normal values of HRV used for this study were as follows: ${ }^{10} \mathrm{SDNN}(141 \pm 39$ milliseconds [ms]) and SDANN

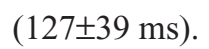

The data were then entered into the computer for statistical analysis using SPSS version 16 software. Data were represented using descriptive statistics such as tables, graphs, and bar charts. Categorical variables were expressed as proportions and percentages while continuous variables were expressed as means \pm standard deviations (SDs).

\section{Results}

\section{Demography and clinical indications}

Demography and clinical characteristics of the studied patients are shown in Table 1. Out of the 310 patients reviewed, 134 were males (43.2\%) while 176 were females $(56.8 \%)$. The mean \pm SD age in years and mean body mass index $(\mathrm{BMI}) \pm \mathrm{SD}$ (excluding stroke patients) in $\mathrm{kg} / \mathrm{m}^{2}$ of the study group was $55.60 \pm 17.40$ and $26.38 \pm 5.99$, respectively. The mean $\pm \mathrm{SD}$ age (years) for males and females was $57.40 \pm 17.98$ and $54.23 \pm 16.87$, respectively while the mean \pm SD BMI $\left(\mathrm{kg} / \mathrm{m}^{2}\right)$ for males and females was $25.70 \pm 4.56$ and $26.88 \pm 6.83$, respectively.

Clinical indications for Holter ECG are shown in Table 2. The commonest indication for Holter ECG was palpitation found in 71 (23\%) of the studied patients. Rare

Table I Clinical characteristics of the studied groups

\begin{tabular}{|c|c|c|c|c|}
\hline Parameters & $\begin{array}{l}\text { Number } \\
\text { of patients }\end{array}$ & $\begin{array}{l}\text { Sex } \\
\text { Females: } \mathbf{n}(\%) / \text { males: } \mathbf{n}(\%)\end{array}$ & $\begin{array}{l}\text { Age } \\
\text { (years) }\end{array}$ & $\begin{array}{l}\text { BMI } \\
\left(\mathrm{kg} / \mathrm{m}^{2}\right)\end{array}$ \\
\hline Palpitation & 71 & $35(49.3 \%) / 36(50.7 \%)$ & $53.13 \pm 20.73$ & $26.60 \pm 5.19$ \\
\hline Syncope & 49 & $35(71.4 \%) / 49$ (28.6\%) & $59.20 \pm 9.75$ & $25.87 \pm 3.37$ \\
\hline $\mathrm{HHF}$ & 45 & $23(51.0 \%) / 22(49.0 \%)$ & $65.73 \pm 13.92$ & $25.02 \pm 4.31$ \\
\hline HHD with LVH & 42 & $27(64.3 \%) / 15$ (35.7\%) & $57.14 \pm 11.72$ & $28.55 \pm 10.37$ \\
\hline Stroke & 33 & $17(51.5 \%) / 16(48.5 \%)$ & $63.70 \pm 12.16$ & - \\
\hline Known Arrhythmia & 13 & $9(69.2 \%) / 4(30.8 \%)$ & $49.69 \pm 18.50$ & $24.95 \pm 5.09$ \\
\hline Unexplained DOE & 10 & $4(40.0 \%) / 6(60.0 \%)$ & $59.20 \pm 9.75$ & $25.87 \pm 3.37$ \\
\hline Dizziness & 10 & $3(30.0 \%) / 7$ (70.0\%) & $39.10 \pm 20.04$ & $27.08 \pm 4.32$ \\
\hline DM with Autonomic neuropathy & 10 & $7(70.0 \%) / 3(30.0 \%)$ & $54.50 \pm 9.21$ & $28.86 \pm 4.32$ \\
\hline DCM & 7 & $4(57.1 \%) / 3(42.9 \%)$ & $61.29 \pm 14.19$ & $22.40 \pm 3.50$ \\
\hline Chest pain & 6 & $2(33.3 \%) / 4(66.7 \%)$ & $49.33 \pm 19.77$ & $30.32 \pm 5.32$ \\
\hline VHD & 4 & $3(75.0 \%) / I(25.0 \%)$ & $47.25 \pm 19.60$ & $19.52 \pm 5.47$ \\
\hline Pacemaker rhythm & I & $\mathrm{I}(\mathrm{I} 00.0 \%) / 0(0.0 \%)$ & $72.00 \pm 0.00$ & $20.00 \pm 0.00$ \\
\hline Not Indicated & 9 & 7 (77.8\%)/2 (22.2\%) & $52.67 \pm 13.74$ & $25.02 \pm 4.53$ \\
\hline Total & 310 & I 76 (56.8\%)/I 34 (43.2\%) & $55.60 \pm 17.40$ & $\begin{array}{l}26.38 \pm 5.99 \\
\text { (excluding stroke) }\end{array}$ \\
\hline
\end{tabular}

Abbreviations: BMI, body mass index; HHF, hypertensive heart failure; HHD, hypertensive heart disease; LVH, left ventricular hypertrophy; DOE, dyspnea on exertion; DM, diabetes mellitus; DCM, dilated cardiomyopathy; VHD, valvular heart disease. 
Table 2 Clinical indication

\begin{tabular}{lll}
\hline Clinical indication & $\begin{array}{l}\text { Number of } \\
\text { patients }(\mathbf{N}=\mathbf{3} \text { I 0) }\end{array}$ & $\%$ \\
\hline Palpitation & 71 & 23.0 \\
Syncope & 49 & 15.8 \\
HHF & 45 & 14.5 \\
HHD with LVH & 42 & 13.6 \\
Stroke & 33 & 10.6 \\
Known arrhythmia & 13 & 4.2 \\
Unexplained DOE & 10 & 3.2 \\
Dizziness & 10 & 3.2 \\
DM with AUT neuropathy & 10 & 3.2 \\
DCM & 7 & 2.3 \\
Chest pain & 6 & 1.9 \\
VHD & 4 & 1.3 \\
Pacemaker rhythm & 1 & 0.3 \\
Not indicated & 9 & 2.9 \\
Total & 310 & 100 \\
\hline
\end{tabular}

Abbreviations: $\mathrm{HHF}$, hypertensive heart failure; $\mathrm{HHD}$, hypertensive heart disease; LVH, left ventricular hypertrophy; DOE, dyspnea on exertion; DM, diabetes mellitus; AUT, autonomic; DCM, dilated cardiomyopathy; VHD, valvular heart disease.

indications are chest pain (1.9\%), valvular heart disease (1.3\%), and pacemaker rhythm $(0.3 \%)$ as shown in Figure 1. According to the recommendations of American College of Cardiology/American Heart Association (ACC/AHA) guidelines ${ }^{10}$ for ambulatory ECG; 131 patients (43.2\%) had class I indication, 81 patients $(26.1 \%)$ and 89 patients $(28.7 \%)$ had class IIb and class III indications for Holter ECG, respectively.

Table 3 shows the distribution of clinical indications for Holter ECG by age group. Of the studied patients, $27.1 \%$ are between the ages of 51 and 60 years while $9.7 \%$ of the studied patients are between the ages of 15 and 30 years.

\section{Holter ECG findings}

Premature ventricular complex (PVC) was the commonest type of arrhythmia accounting for $51.5 \%$ among patients with arrhythmia, followed by premature atrial complex $15 \%$, as shown in Table 4 . The male to female ratio of PVC among the studied patients is $0.9: 1.1$. Nineteen point six percent of patients $<50$ years had PVC while $31.2 \%$ of patients $\geq 50$ years had PVC. Ventricular arrhythmia was found more prevalent in dilated cardiomyopathy (DCM) patients (85.7\%), hypertensive heart failure (HHF) patients (40.1\%), stroke patients (36.3\%), and patients with palpitation (32.8\%). Eighty percent of diabetes mellitus (DM) patients with autonomic neuropathy and $71.4 \%$ of hypertensive heart disease (HHD) patients had normal Holter ECG findings. Six (1.9\%) out of the studied patients had sustained ventricular tachycardia (VT) (Figure 2), while eleven patients (3.6\%) had severe bradycardia (heart rate [HR] $<40$ beats per minute). Eleven patients (3.6\%) had atrial fibrillation (AF) with $45.5 \%$ of them being HHF patients. Two point two percent of patients $<50$ years had AF while $4.1 \%$ of patients $\geq 50$ years had AF. One patient $(0.3 \%)$ had pacemaker tachycardia. Ninety-two (29.7\%) patients had significant sinus pauses. Seventy-six (24.5\%) patients had multiple ST depression in channel 1.

Applying Lown's grading of $\mathrm{PVCs}^{11}$ among patients with PVC; Lown's grade 4 was more prevalent in DCM patients $(66.7 \%)$, patients with palpitation (61\%), and HHF patients (55.2\%), while Lown's grade 2 was more common in patients with dizziness (60\%), stroke patients (46\%), and HHD patients (29.4\%), respectively.

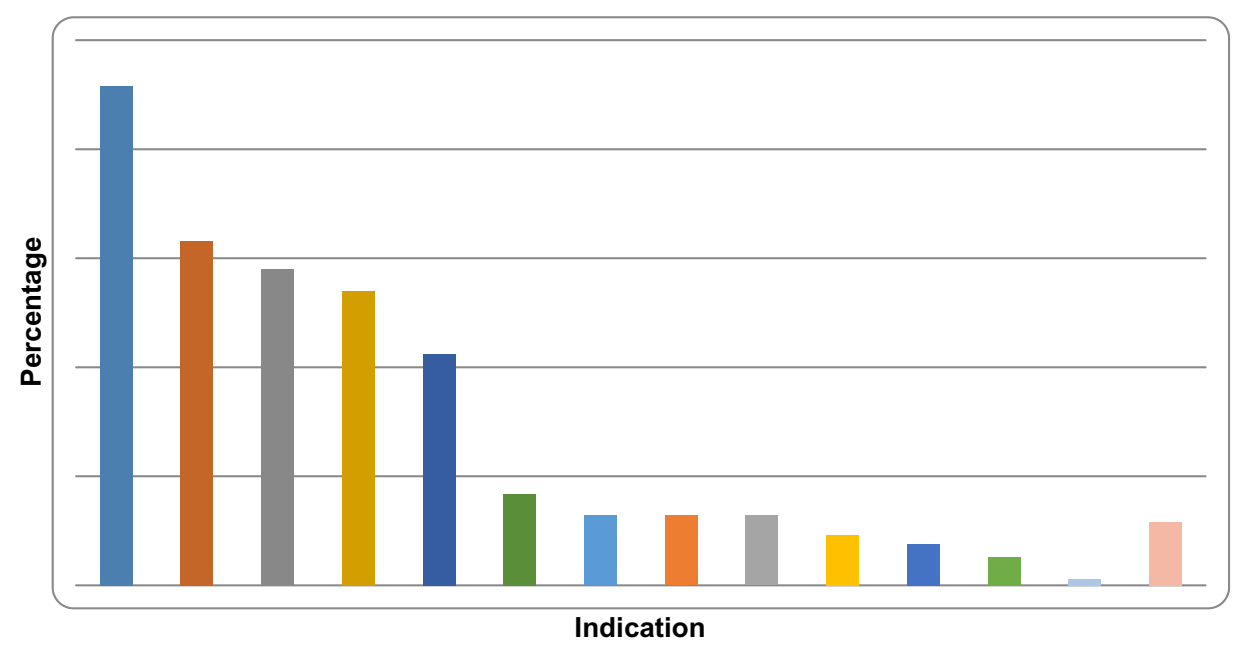

\author{
- Palpitation, 22.9 \\ - Syncope, 15.8 \\ - $\mathrm{HHF}, 14.5$ \\ - HHD with LVH, 13.5 \\ - Stroke, 10.6 \\ - Arrhythmia, 4.2 \\ - Une DOE, 3.2 \\ - Dizziness, 3.2 \\ DCM, 2.3 \\ - DM with AUT Nero, 3.2 \\ - Chest pain, 1.9 \\ - VHD, 1.3 \\ - Pacemaker, 0.3 \\ Not Indicated, 2.9
}

Figure I Bar chart showing the clinical indications for Holter ECG.

Abbreviations: ECG, electrocardiography; HHF, hypertensive heart failure; HHD, hypertensive heart disease; LVH, left ventricular hypertrophy; Une DOE, unexplained dyspnea on exertion; DM, diabetes mellitus; AUT Nero, autonomic neuropathy; DCM, dilated cardiomyopathy; VHD, valvular heart disease. 


\section{HRV}

The mean (SD) minimum and maximum HR of the studied patients was $45.70 \pm 16.60$ and $153.34 \pm 47.68$, respectively. The mean (SD) minimum and maximum HR for females was $44.59 \pm 16.38$ and $159.57 \pm 49.58$ while for males, the mean (SD) minimum and maximum HR was $47.16 \pm 16.82$ and $145.15 \pm 43.91$, respectively.

The HRV using SDNN average (ms) and SDANN average (ms) of the studied patients was 107.34 \pm 52.74 and 75.47 \pm 48.63 , respectively. Using SDNN average (ms), the HRV of patients with palpitation, HHF patients, stroke patients, and DM patients with autonomic neuropathy were 107.32 $\pm 49.61,117.20 \pm 65.93,79.15 \pm 49.15$, and 66.50 \pm 15.54 , respectively. The HRV using SDANN average (ms) of patients with palpitation, HHF patients, stroke patients, and DM patients with autonomic neuropathy were $77.39 \pm 62.34$,

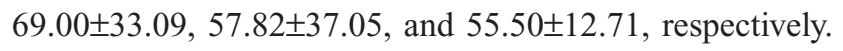
Using SDNN, there was a significant difference in the HRV of stroke and HHF, DM with autonomic neuropathy and HHF, and DM with autonomic neuropathy and palpitation patients, $(F=4.896, P<0.05)$.

\section{Discussion}

Palpitation of unknown etiology was the commonest indication in our study (23\%). Katibi et $\mathrm{al}^{5}$ reported palpitation as the commonest indication (25\%). This study shows that cardiac arrhythmia was prevalent in the study group (54.2\%), with more females affected than males and that prevalence increases with age. Omotoso et $\mathrm{al}^{12}$ reported that females were slightly more affected with arrhythmia than males and that prevalence of arrhythmia increases with age especially after the fourth decade. The clinical indication in 89 patients $(28.7 \%)$ of the study group was class III according to the recommendations of ACC/AHA guidelines ${ }^{10}$ for ambulatory ECG. Piccirilli et $\mathrm{al}^{13}$ reviewed the clinical indications of 2,489 consecutive Holter ECG recordings and reported that 1,298 (52\%) were clearly appropriate (class I), 311 (13\%) as probably or possibly appropriate, and 880 (35\%) as inappropriate (class III).

Eighty-seven out of 310 (28.1\%) of our study group were hypertensive patients. Hypertension has two major consequences on the heart - left ventricular hypertrophy $(\mathrm{LVH})$, morphological and functional alterations of the coronary macro- and micro-vessels. These anatomical and tissue changes caused by hypertension account for the higher incidence of atrial and ventricular arrhythmias as compared to normal population. ${ }^{14,15}$

PVC was the commonest arrhythmic pattern accounting for $51.5 \%$ among patients with arrhythmia. Katibi et $\mathrm{al}^{5}$ also reported PVC (47.6\%) as the commonest arrhythmic pattern in his study. Talib et al, ${ }^{16}$ in a study of 75 healthy individuals using Holter ECG, reported ventricular arrhythmias as the commonest (45.3\% had ventricular ectopic beats [VEBs]). Sultana et al, ${ }^{15}$ in a study of cardiac arrhythmia and LVH in systemic hypertension, reported ventricular arrhythmias (PVCs) as the commonest arrhythmic pattern $(25.6 \%$ in males, $21.8 \%$ in females). The lower proportion reported in the study by Sultana et al may be attributable to the fact

Table 3 Distribution of clinical indications for Holter ECG by age group

\begin{tabular}{|c|c|c|c|c|c|c|c|}
\hline \multirow{3}{*}{$\begin{array}{l}\text { Parameters } \\
\text { Clinical indications }\end{array}$} & \multicolumn{7}{|c|}{ Age range in years } \\
\hline & $15-30$ & $3 I-40$ & $4 I-50$ & $5 I-60$ & $61-70$ & $>70$ & Total \\
\hline & $\mathbf{N}(\%)$ & $\mathbf{N}(\%)$ & $\mathbf{N}(\%)$ & $\mathbf{N}(\%)$ & $\mathbf{N}(\%)$ & $\mathbf{N}(\%)$ & $\mathbf{N}$ \\
\hline Palpitation & $13(18.3)$ & $7(9.9)$ & $8(I 1.3)$ & 14 (19.7) & I5 (2I.I) & $14(19.7)$ & 71 \\
\hline Syncope & $7(14.3)$ & II (22.5) & $5(10.2)$ & $14(28.6)$ & $6(12.2)$ & $6(12.2)$ & 49 \\
\hline $\mathrm{HHF}$ & $0(0)$ & $3(6.7)$ & $3(6.7)$ & $8(17.7)$ & $13(28.9)$ & $18(40.0)$ & 45 \\
\hline HHD with LVH & I (2.4) & $3(7.1)$ & $6(14.3)$ & I5 (35.7) & $12(28.6)$ & $5(11.9)$ & 42 \\
\hline Stroke & $0(0)$ & $0(0)$ & $5(15.1)$ & $12(36.4)$ & $7(2 \mid .2)$ & $9(27.3)$ & 33 \\
\hline Known Arrhythmia & $2(15.4)$ & $2(15.4)$ & $3(23.1)$ & I (7.6) & $2(15.4)$ & $3(23.1)$ & 13 \\
\hline Unexplained DOE & $0(0)$ & I (I0.0) & $0(0)$ & $4(40.0)$ & $4(40.0)$ & I $(10.0)$ & 10 \\
\hline Dizziness & $5(50)$ & $0(0)$ & I (I0.0) & $3(30.0)$ & $0(0)$ & $I(10.0)$ & 10 \\
\hline DM with AUT neuropathy & $0(0)$ & $2(20.0)$ & $0(0)$ & $5(50.0)$ & $3(30.0)$ & $0(0)$ & 10 \\
\hline DCM & $0(0)$ & $0(0)$ & I (I4.3) & $3(42.8)$ & $2(28.6)$ & I (I4.3) & 7 \\
\hline Chest pain & I (I6.7) & $2(33.3)$ & $0(0)$ & I (I6.7) & I (16.7) & I (I6.7) & 6 \\
\hline VHD & I $(25.0)$ & $0(0)$ & I $(25.0)$ & I (25.0) & I $(25.0)$ & $0(0)$ & 4 \\
\hline Pacemaker rhythm & $0(0)$ & $0(0)$ & $0(0)$ & $0(0)$ & $0(0)$ & $I(100)$ & 1 \\
\hline Not indicated & $0(0)$ & $3(33.3)$ & $0(0)$ & $3(33.3)$ & $3(33.3)$ & $0(0)$ & 9 \\
\hline Total & $30(9.7)$ & $34(11.0)$ & $33(10.6)$ & $84(27.1)$ & $69(22.3)$ & $60(19.3)$ & 310 \\
\hline
\end{tabular}

Abbreviations: ECG, electrocardiography; HHF, hypertensive heart failure; HHD, hypertensive heart disease; LVH, left ventricular hypertrophy; DOE, dyspnea on exertion; DM, diabetes mellitus; AUT, autonomic; DCM, dilated cardiomyopathy; VHD, valvular heart disease. 


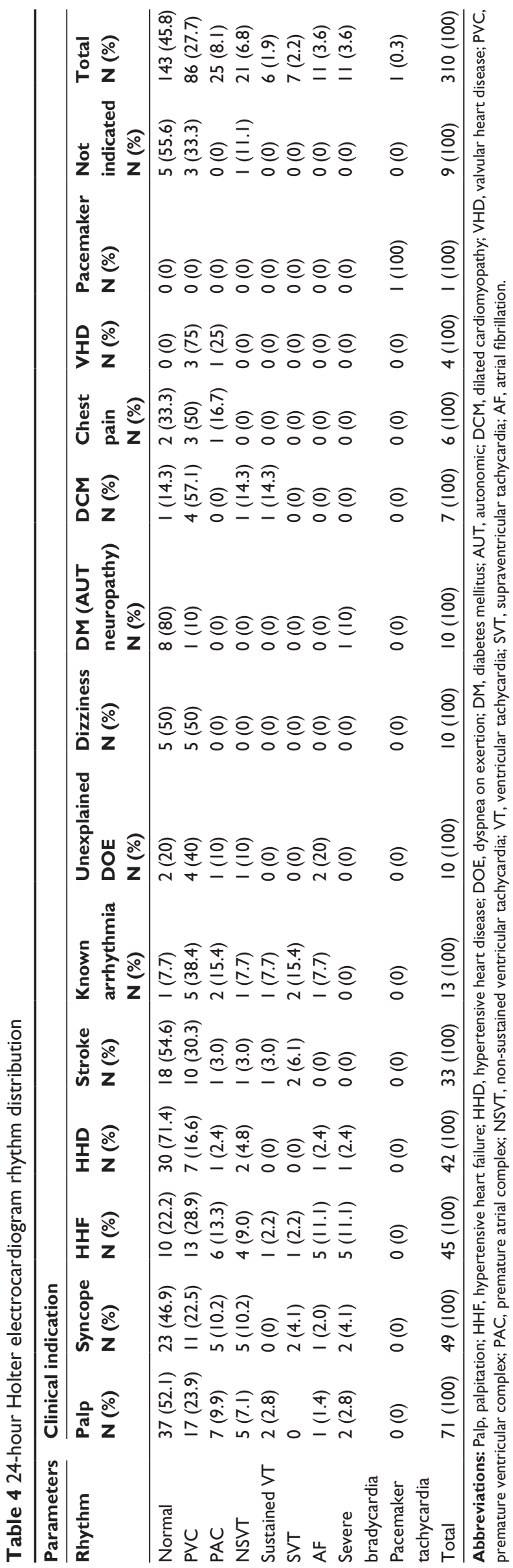

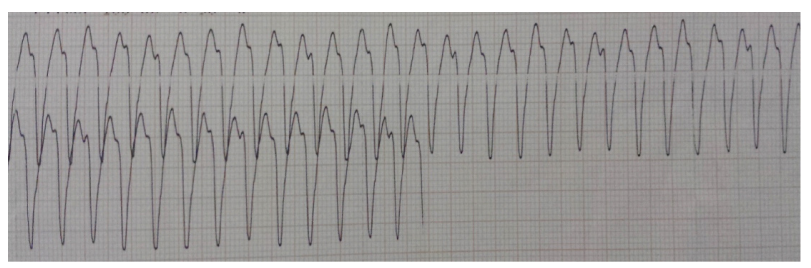

Figure 2 Seventy year-old woman, known hypertensive with an episode of ventricular tachycardia during 24-hour Holter ECG.

Abbreviation: ECG, electrocardiography.

that 24-hour Holter ECG was carried out only on patients who complained of palpitation. Ventricular arrhythmia was found more prevalent in DCM patients (85.7\%), HHF patients (40.1\%), stroke patients (36.2\%), and patients with palpitation (32.8\%). Heart failure irreversibly damages myocardial fibers which may serve as foci for various forms of arrhythmias. ${ }^{17,18}$ Lasisi et $\mathrm{al}^{7}$ reported that ambulant outpatients with chronic heart failure have significantly higher prevalence of ventricular arrhythmia and narrow HRV compared to healthy individuals of comparable age and sex. Adebayo et $\mathrm{al}^{8}$ reported ventricular arrhythmia in $47 \%$ of HHF patients. The atherosclerotic risk in communities (ARIC) study ${ }^{19}$ of more than 15,000 African-American and White men and women reported that frequent or complex VEBs are also associated with hypertension, and that VEBs increase with increased electrocardiographic estimate of left ventricular mass. LVH and complex ventricular arrhythmias are significant predictors of sudden cardiac death. ${ }^{20-22}$ Ajayi and Ajayi, ${ }^{23}$ in a study of 24-hour Holter arrhythmic patterns of 37 HHF patients with or without valvular heart disease, reported that LVH increases arrhythmias but multi-valvular regurgitation predisposes to greater supraventricular tachycardia and complex ventricular arrhythmias. Three point six percent of studied patients had AF. AF is the most commonly sustained arrhythmia in adults and is associated with an increased risk of cardiovascular morbidity, mortality, and stroke. ${ }^{24,25}$ Hypertension is one of the important independent risk factors for the development of $\mathrm{AF}^{26}$ Omotoso et $\mathrm{al}^{12}$ reported $5.2 \%$ in a study of 2,017 Nigerians with HHD using resting ECG. The higher proportion in his study may be attributable to the fact that his study groups had a pre-existing heart disease. Familoni et $\mathrm{a}^{27}$ reported that AF was associated with increased mortality rates among patients with advanced heart failure. Most ECG monitoring data from acute stroke units indicate a frequency of arrhythmia of $40 \%-60 \%{ }^{28}$ It is most significant to note that six patients $(1.9 \%)$ with PVC in this study had periods of sustained VT. Some studies ${ }^{11,29}$ reported that VT can degenerate to malignant ventricular arrhythmia and that it is also a risk factor for sudden cardiac death. 
The HRV using SDNN was reduced in DM patients with autonomic neuropathy $(66.50 \pm 15.54)$ and stroke patients (79.15 \pm 49.15$)$. Adebayo et $\mathrm{al}^{8}$ reported significantly reduced HRV in type II DM patients $(81.03 \pm 26.33)$ when compared with hypertensive patients. Boer-Martins et $\mathrm{al}^{30}$ reported that decreased HRV in type II DM patients with resistant hypertension, when compared with non-type II DM group. Korpelainen et $\mathrm{al}^{31}$ reported that stroke patients have an impaired autonomic control as evidenced by abnormality of HRV, which may have unfavorable prognosis in acute stroke.

\section{Conclusion}

Palpitation and syncope were the commonest indications for Holter ECG among our subjects. The commonest arrhythmic patterns were PVC and premature atrial complex, with ventricular arrhythmia being more prevalent in DCM and HHF patients. There was a reduction in HRV in patients with stroke and diabetic autonomic neuropathy.

\section{Disclosure}

The authors have no conflicts of interest to disclose.

\section{References}

1. Araoye MA. Basic Electrocardiography. Ilorin Nigeria: Nathadex Publishers Ltd; 2004:85-134.

2. Zimetbaum P, Goldman A. Ambulatory Arrhythmia Monitoring: Choosing the Right Device. Circulation. 2010;122(16):1629-1636.

3. Takase B, Kurita A, Noritake M, et al. Heart Rate Variability in Patients with Diabetes Mellitus, Ischemic Heart Disease and Congestive Heart Failure. J Electrocardiol. 1992;25(2):79-88.

4. Gasilin VS, Stetsenko AE, Kruglov VA, Boikova OI, Chernysheva GV. [Possibilities of Holter ECG Monitoring in Detecting Arrhythmias and Myocardial Ischemia in Persons with Ischemic Heart Disease Risk Factors]. Kardiologiia. 1989;29(3):10-13. Russian.

5. Katibi IA, Beshir S, Mudashiru Z. Ambulatory 24-hour Holter Electrocardiography among Nigerians: Our Experience at a Referral Cardiac Centre in Lagos, Nigeria. Nigerian Medical Journal. 2006; 47(2):25-27.

6. Adebola AP, Daniel FA, Lasisi GT, et al. 24-hour Holter Monitoring at the Lagos State University Teaching Hospital-a report of 85 cases. Nigerian Journal of Clinical Medicine. 2009;2(2).

7. Lasisi GT, Adebola AP, Ogah OS, Daniel FA. Prevalence of Ventricular Arrhythmia and Heart Rate Variability Pattern in Chronic Heart Failure. Niger Postgrad Med J. 2012;19(3):157-162.

8. Adebayo RA, Ikwu AN, Balogun MO, et al. Evaluation of the Indications and Arrhythmic Patterns of 24-hour Holter Electrocardiography among Hypertensive and Diabetic Patients seen at OAUTHC, Ile-Ife Nigeria. Diabetes Metab Syndr Obes. 2014;7:565-570.

9. MT-101/MT-200 [package insert]. Baar, Switzerland: Schiller; 2004.

10. Crawford MH, Bernstein SJ, Deedwania PC, et al. ACC/AHA Guidelines for Ambulatory Electrocardiography. A report of the American College of Cardiology/American Heart Association Task Force on Practice Guidelines (Committee to Revise the Guidelines for Ambulatory Electrocardiography). Developed in collaboration with the North American Society for Pacing and Electrophysiology. J Am Coll Cardiol. 1999;34(3):912-948.
11. Lown B, Wolf M. Approaches to Sudden Death from Coronary Heart Disease. Circulation. 1971;44(1):130-142.

12. Omotoso AB, Opadijo OG, Araoye MA. Arrhythmias in Hypertensive Heart Disease: A Study of 2,017 Nigerian Patients. Nig Qt J Hosp Med. 1997;7(4):310-313.

13. Piccirilli S, Gallagher MM, Vellini M, et al. Appropriateness of ECG Holter Request in Outpatient Services: A Prospective Study. J Cardiovasc Med (Hagerstown). 2007;8(7):517-520.

14. Yiu KH, Tse HF. Hypertension and Cardiac Arrhythmias: a Review of the Epidemiology, Pathophysiology and Clinical Implications. J Hum Hypertens. 2008;22(6):380-388.

15. Sultana R, Sultana N, Rashid A, et al. Cardiac Arrhythmia and Left Ventricular Hypertrophy in Systemic Hypertension. J Ayub Med Coll Abbotabad. 2010;22(4):155-158.

16. Talib SH, Mulay PY, Patil AN. Twenty-four Hour Ambulatory Holter Monitoring and Heart Rate Variability in Healthy Individuals. JIACM. 2005;6(2):136-141.

17. Pohwidz SM, Corr PB. Biochemical and Electrophysiological Alterations Underlying Ventricular Arrhythmias in the Failing Heart. Eur Heart J. 1994;15 Suppl D:145-154.

18. Araoye MA, Olowoyeye JO. The Clinical Spectrum of Hypertensive Heart Failure: A Point-score System for Solving an Old Problem. East Afr Med J. 1984;61(4):306-315.

19. Simpson RJ Jr, Cascio WE, Schreiner PJ, Crow RS, Rautaharju PM, Heiss G. Prevalence of Premature Ventricular Contractions in a Population of African-American and White Men and Women: the Atherosclerotic Risk in Communities (ARIC) Study. Am Heart J. 2002;143(3): 535-540.

20. Schillaci G, Verdechia P, Borgioni C, et al. Association Between Persistent Pressure Overload and Ventricular Arrhythmias in Essential Hypertension. Hypertension. 1996;28(2):284-289.

21. Saadeh AM, Jones JV. Predictors of Sudden Cardiac Death in Never Previously Treated Patients with Essential Hypertension: Long Term Follow-up. J Hum Hypertens. 2001;15(10):677-680.

22. Dzudie A, Milo O, Edwards C, et al. Prognostic Significance of Electrocardiographic Abnormalities for Mortality Risk in Acute Heart Failure: Insight from sub-Saharan Africa Survey for Heart Failure (THESUS-HF). J Card Fail. 2014;20(1):45-52.

23. Ajayi OE, Ajayi AA. Valvular Regurgitations may Increase the Risk of Arrhythmias in Hypertensive Heart Failure in Nigerians. J Cardiovasc Med (Hagerstown). 2013;14(6):453-460.

24. Benjamin EJ, Wolf PA, D’Agostino RB, Silbershatz H, Kannel WB, Levy D. Impact of Atrial Fibrillation on the Risk of Death: the Framingham Heart Study. Circulation. 1998;98:946-952.

25. Stewart S, Hart CL, Hole DJ, McMurray JJ. A Population-based Study of the long-term Risks associated with Atrial Fibrillation: 20-year follow-up of the Renfrew/Paisley study. Am J Med. 2002;113(5):359-364.

26. Benjamin EJ, Levy D, Vaziri SM, et al. Independent Risk Factors for Atrial Fibrillation in a Population-based Cohort: The Framingham Heart Study. JAMA. 1994;271(11):840-844.

27. Familoni OB, Olunuga TO, Olufemi BW. A Clinical Study of Pattern and Factors Affecting Outcome in Nigerian Patients with Advanced Heart Failure. Cardiovasc J Afr. 2007;18(5):308-311.

28. Norris JW, Froggatt GM, Hachinski VC. Cardiac Arrhythmias in Acute Stroke. Stroke. 1978;9(4):392-396.

29. Snyder DW, Sheridan DJ, Sobel BE. Premature Ventricular Complexes; Therapeutic Dilemmas and Decisions. Adv Cardiol. 1980;27: 322-342.

30. Boer-Martins L, Figueiredo VN, Demacq C, et al. Relationship of Autonomic Imbalance and Circadian Disruption with Obesity and Type 2 Diabetes in Resistant Hypertension Patients. Cardiovasc Diabetol. 2011;10:24.

31. Korpelainen J, Sotaniemi K, Maikikallio A, Huikuri HV, Myllylä VV. Dynamic Behaviour of Heart Rate in Ischemic Stroke. Stroke. 1999;30(5):1008-1013. 


\section{Publish your work in this journal}

Vascular Health and Risk Management is an international, peerreviewed journal of therapeutics and risk management, focusing on concise rapid reporting of clinical studies on the processes involved in the maintenance of vascular health; the monitoring, prevention and treatment of vascular disease and its sequelae; and the involvement of metabolic disorders, particularly diabetes. This journal is indexed on PubMed Central and MedLine. The manuscript management system is completely online and includes a very quick and fair peer-review system, which is all easy to use. Visit http://www.dovepress.com/ testimonials.php to read real quotes from published authors.

Submit your manuscript here: http://www.dovepress.com/vascular-health-and-risk-management-journal 